Open Access : ISSN : 1848-7718

Review

\title{
The function and regulation of PD-L1 in immunotherapy
}

\author{
Libin Guo ${ }^{1}$, Yao Lin $^{2}$ and Hang Fai Kwok ${ }^{1 *}$ \\ ${ }^{1}$ Faculty of Health Sciences, University of Macau, Macau SAR \\ ${ }^{2}$ College of Life Sciences, Fujian Normal University, Fuzhou, Fujian Province, China \\ *Corresponding Author: E-mail: hfkwok@umac.mo; Tel.: +853 8822 4991; Fax: +853 88224991 \\ Received: September 18, 2017; Revised: September 27, 2017; Published: September 29, 2017
}

\begin{abstract}
$P D-L 1$, also known as B7-H1, is a type I transmembrane protein, which is expressed in different kinds of tumor cells. It is correlated with poor clinical outcome of patients with various types of tumors. PD-L1 can regulate tumor microenvironment or tumor related immune response through suppressing $T$ cell or NK cell mediated immune response. $P D-L 1$ expression is regulated by various cytokines, such as $L P S, G M-C S F, I L-4$, TGF-B, TNF- $\alpha$. PD-1 and PD-L1 are the members of B7 and CD28 superfamily, respectively. The B7/CD28 interaction plays a central role in immune tolerance. $P D-L 1$ can bind to $P D-1$, which leads to the suppression of lymphocyte activation and apoptosis of lymphocytes. Anti-PD-L1 therapy is one of the immunotherapies to treat cancer (especially solid tumor). PD-L1 expression may be associated with efficacy of anti PD-1/PD-L1 therapy. In this review, we will focus on the regulation mechanism of PD-L1 expression, and describe the role of $P D-1 / P D-L 1$ binding on the anti-PD-1/PD-L1 therapy.
\end{abstract}

\section{Keywords}

Immune checkpoint; PD-L1 expression; Signal pathway; Regulation mechanism.

\section{Introduction}

Cancer is the first leading cause of death in China and second leading cause of death in United States in recent years [1,2]. Although, the cancer death rates have declined over 2 decades, the death rates caused by cancers of uterine corpus and liver are still increasing. It is estimated that by 2030 about 13-17 million people will die from cancer [3]. Cancer is a major public health issue, and the search for advanced detection methods and novel treatments are important. Cancer treatments include various types of therapies, such as surgery, radiation, chemotherapy, biological therapy and targeted therapy [4-8]. Among these therapies, immunotherapy for cancer has now become a new standard strategy to treat cancer. With the approval of rituximab and trastuzumab, immunotherapy the field of cancer therapy changed considerably [9]. Over recent decades, immunotherapy has been used for solid and hematological malignances treatment [10]. There are several types of immunotherapy, including vaccines, monoclonal antibodies, T cell therapy, oncolytic virus therapy, non-specific immunotherapies [11-15]. As one of approaches of immunotherapy, antibody-based cancer therapy employs monoclonal antibodies targeting receptor tyrosine kinase (RTKs), immune checkpoint inhibitor, or other membrane antigens. Antibodies targeting RTKs (such as human epidermal growth factor receptor 2 (HER2) and extracellular signal regulated kinase (ERK)) are often limited by resistance. For example, colorectal cancer patients are 
resistant to cetuximab and panitumumab (anti- epidermal growth factor receptor (EGFR) antibodies) when the tumor has a mutated Ras-protein [16, 17]. Bispecific antibodies (bsAb) and Homo-combinations of antibodies targeting RTKs are employed to improve sensitivity of patients to antibodies[18]. Immune checkpoint inhibitor, such as anti-programmed cell death protein 1 (PD-1) antibody, anti-programmed death ligand 1 (PD-L1) antibody and anti-cytotoxic T-lymphocyte-associated protein 4 (CTLA-4) antibody, can enhance the ability of cytotoxic T cells to recognize tumor without limitation by resistance [19]. PD-L1 is known as B7 homolog $1(B 7-H 1)$ or cluster of differentiation (CD274) and is recognized as a cell surface protein belonging to B7 superfamily. Many studies have reported that PD-L1 can suppress T lymphocyte activation through interacting with some PD-L1 receptor, such as PD-1.

\section{PD-L1 directed therapy of cancer}

Many studies showed that PD-L1 expression is present in various kinds of tumors, which suggested that PD-L1 may be closely related with cancer. Liu et al. demonstrated that PD-L1 expression was found in multiple myeloma plasma cells, but not in cells which were isolated from monoclonal gammopathy or healthy donors [20]. PD-L1 expression has not only been found on glial tumor cells, but also on various brain metastases $[21,22] .66 \%$ of freshly isolated Head and neck squamous cell carcinoma (HNSCC) showed constitutive expression of PD-L1 [23]. Except for cancers mentioned above, upregulation of PD-L1 has also been found in other common cancers, such as melanoma, ovarian cancer, lung cancer, urothelial carcinoma, esophageal cancer, cervical cancer, pancreatic cancer and Wilms tumor [24-31].

Recent clinical data showed that increased expression of PD-L1 was closely related with a poor prognosis in chronic hepatitis B virus (HBV) infected hepatocellular carcinoma patients [32]. In breast cancers it was shown that in this disease a higher expression of PD-L1 had a strong link with several characteristics, such as tumor size, American Joint Committee on Cancer (AJCC) primary tumor classification, tumor grade, lymph node status, and high Ki-67 expression [33]. Meanwhile, PD-L1 was also shown to be related to poor prognosis in human breast cancer [33]. Upregulation of PD-L1 was closely related with late stage clinical development and decreased rate of disease-free survival [34]. Sarah et al. reported that PD-L1 was expressed in tumor cells of patients with Epstein-Barr Virus (EBV) infected gastric cancer (GC), but not in other GC cancer cells [35].

Besides, preclinical experiments also showed an effect of PD-L1 on tumor treatment. In an acute myeloid leukemia (AML) model, blockade of PD-L1 by antibodies enhanced immune response against leukemia cells (C1498.GFP cells) in C57BL/6 mice [36]. Meanwhile, CD8+ T cell receiving anti-PD-L1 antibody was shown to increase in livers from C57BL/6 mice compared to control without treatment with antibodies [36]. Iwai et al. showed that in vitro P815 cells transfected with pApuroXS-PD-L1 stably expressed PD-L1, and was susceptible to T cell antigen receptor (TCR)-mediated lysis induced by Cytotoxic $T$ cells [37]. Most importantly, tumorigenesis and invasiveness of these tumor cells was enhanced compared to parental cells which didn't express PD-L1 [37]. The promoting effect of PD-L1 on cancer was also shown by suppression of anti-PD-L1 antibody on the growth of myeloma cells [37].

\section{PD-L1expression in immune diseases}

As a target of immune checkpoint inhibitor, PD-L1 is not only associated with anti-cancer treatment, but also with other immune diseases. PD-L1 has a strong link with autoimmune disease. In non-obese diabetic (NOD) prediabetic murine model, PD-L1 expression was significantly upregulated on infiltrating mononuclear cells in the islet [38]. Mohammed et al. also reported that expression of PD-L1 was found in the inflamed islets of NOD mice, suggesting a regulatory role of PD-L1 on the progression of autoimmune 
diabetes [39]. PD-L1 has been reported to contribute to etiopathogenetic of autoimmune diseases in mouse models. Mohammed et al. reported that blockade of PD-L1 by monoclonal antibodies (mAbs) against PD-L1 led to diabetes in female NOD mice [39]. The NOD mouse model is useful for studying diabetes caused by autoimmune process [40]. Blockade of PD-1/PD-L1 interaction didn't induce diabetes in NOR mice, showing the specific islet cell toxicity by mAbs treatment [39]. Bing et al. reported that in $\mathrm{BALB} / \mathrm{c}$ mice, blockade of PD-L1 remarkably increased incidence of experimental autoimmune encephalomyelitis (EAE) in the presence of myelin oligodendrocyte glycoprotein (MOG) peptide 35-55 [41]. Furthermore, in myelin proteolipid protein (PLP) peptide 139-151 immunized B10.S mice, blockade of PD-L1 also significantly enhanced severity of EAE [41]. PD-L1 deficiency mice were completely susceptible to EAE after E2 (known as 17 $\beta$-estradiol, an estrogen) treatment [42]. This study also reported that the protective effect against EAE mediated by $E 2$ was significantly reduced in recipient mice transfected with PD-L1-/- B-cell [42]. Therefore PD-L1 in B cells may be crucial for the protective effect of estrogen against EAE. Enhanced expression of PD-L1 was present on ductal and acinar epithelial cells in the salivary glands of patients with Sjogren's syndrome [43]. Increased expression of PD-L1 has also been found on T cells, B cells as well as monocytes of patients with Systemic Lupus Erythematosus (SLE), implying that PD-L1 might be correlated with SLE disease [44]. The expression of PD-L1 increased on mononuclear cells in the lamina propria of inflammatory bowel disease (IBD) patients, as well as on mononuclear cells in the lamina propria in experimental colitic mice [45].

\section{$P D-L 1$ in virus associated disease}

Besides, PD-L1 is also associated with chronic viral infection and chronic inflammatory diseases. Upregulated expression of PD-L1 was found in livers of patients infected with HBV compared with healthy donors [46]. Previous studies showed that most of Merkel Cell Carcinoma (MCC) were linked to Merkel Cell Polyomavirus (MCPYV) infection [47]. Enhanced expression of PD-L1 was found in MCPyV infected MCC cells compared to MCPyV-negative MCC cells [48]. It was reported that Interferon (IFN)- $\gamma$ had an effect on increasing the number of CD8+ cytotoxic T lymphocytes (CTLS) when infected by the virus [49]. Blockade of PD-L1 enhanced the ability of CD8+ CTLs to produce IFN- $\gamma$ through an increase in the number of IFN- $\gamma$ producing HBV-specific CTLs [50]. Daniel et al. reported that in Lymphocytic Choriomeningitis virus (LCMV) infected mice blockade of PD-L1 and PD-1 interaction restored the ability of exhausted CD8 T cell to kill infected cells [51]. The PD-L1/PD-1 pathway has also been found to mediate the function of virus-specific exhausted CD8 + T cell in human immunodeficiency virus (HIV) infected patients in several studies [51]. Dai et al. showed that blockade of interaction of PD-1/PD-L1 by anti-PD-L1 restored immune response generated by CD8+ T cell after being infected by HIV [52]. Anti-PD-L1 antibody also enhanced proliferation and cytokine production of hepatitis C virus (HCV)-specific CD8 cells during chronic HCV infection in the study reported by Simona et al. [53]. The result of these studies suggested that PD-L1 can inhibit the immune response during chronic viral infection [54]. PD-L1 was involved in intestinal mucosal inflammation, such as ulcerative colitis. In severe combined immune-deficient (SCID) mice, which were reconstituted with CD45RBhigh CD4+ T cells, blockade of PD-L1 by mAbs against B7-H1 suppressed wasting disease with colitis [45].

Role of PD-L1 in efficacy of treatment

Pre-clinical data showed that the anticancer effect of anti-PD-L1 antibody is different kinds of cancer cells. Meanwhile, clinical activity of anti-PD-L1 antibodies has been observed in various malignancies, such as melanoma, non-small cell lung cancer, squamous head and neck cancer, microsatellite-unstable 
colorectal cancer, and other types of cancers [55-58]. A predictive role of PD-L1 expression and TIL (tumor infiltrating lymphocytes) has been found in lung cancer patients receiving anti-PD-1/PD-L1 immunotherapy and could be used to improve clinical interpretations [59]. However, PD-L1 expression can be constitutive and inducible. Induced PD-L1 upregulation is regulated by various other cytokines, such as IFN, Tumor necrosis factor (TNF)- $\alpha$ and Toll-like receptor (TLR) etc. [60]. Most importantly, PD-L1 upregulation can also improve survival of mice with lung tumor, which received anti-PD-L1 treatment [61]. This review will discuss the basic structure of PD-L1, which is important for PD-L1 regulation and therapy. Besides, this review will also discuss regulation and signaling pathway of PD-L1, which can influence anti-PD-L1 immunotherapy.

\section{Structure of PD-L1}

PD-L1 was found by searching the expressed sequence tag database (generated from dendritic cells and activated macrophages) for molecules which contain homology to B7-1 and B7-2 [62]. PD-L1 is encoded by the CD274 gene, which is situated on mouse chromosome 19 and human chromosome 9 at a band p24. PD-L1 is a 40kDa protein containing 290 amino acid. Human PD-L1 shares $70 \%$ homology in amino acids with mouse PD-L1 [63]. Mazanet et al. reported that the promoter region of CD274 gene consisted several elements responded to IFN- - , which was necessary for upregulation of PD-L1 expression mediated by IFN- $\gamma$ [64]. PD-L1 exerts a role as a type I transmembrane protein and contains four domains [56]. They are Ig (immunoglobulin) V-like domain, Ig C-like domain, and hydrophobic transmembrane domain, as well as cytoplasmic domains, encoded by single exon sequences [62]. The schematic diagram and structure of PDL1 is shown in Figure 1. The Ig V-like domain and Ig C-like domain are two anti-parallel $\beta$ sandwich immunoglobulin superfamily (Ig SF) domains, which are related to domains of immunoglobulins $[65,66]$. The Ig V-like domain is formed by BED and AGFCC' $C^{\prime \prime} \beta$ sheets, and necessary for interaction of PD-L1 and B7-1 in murine [67]. What's more, the PD-L1:PD-1 binding interface is also on its Ig V-like domain. The Ig C domain of PD-L1 has C1-set domains with $\beta$-strands forming ABED and CFG sheets [66]. The cytoplasmic domain which is encoded by the last exon is about 30 amino acids, and highly conserved in all species reported [23]. While a potential site of PD-L1 which could be phosphorylated by Protein Kinase C (PKC) is on its intracellular domain [23].

\section{Regulation of PD-L1}

PD-L1 expression is present on antigen-presenting cells (APCs), such as human monocytes, as well as activated human and murine dendritic cells. Moreover, PD-L1 is also expressed in nonlymphoid tissues such as heart and lung, thymus, kidney. PD-L1 is easily induced by pro-inflammatory cytokines on different kinds of cells, which is shown in Figure 2.

PD-L1 can be induced by IFN- $\gamma$ and TLR ligands in MM plasma cells [20]. This study revealed that blockade of mitogen-activated protein kinase (MAPK)/ERK pathway and inhibition of signal transducer and activator of transcription 1 (STAT1) suppressed the enhanced expression of PD-L1 induced by IFN- $\gamma$ [20]. Meanwhile, inhibition of the Myeloid differentiation primary response gene 88 (MyD88) and TNF receptor-associated factor 6 (TRAF6) has been reported to inhibit PD-L1 expression either induced by TLR ligands or by IFN- $\gamma$ [20]. In human lung cancer cells interferon regulatory factor-1 (IRF-1) was necessary for induction of PD-L1 expression mediated by IFN- - in STAT1-manner [68]. Besides, a recent study also showed that enhanced expression of PD-L1 induced by TLR also was dependent on IL-, IL-10 and STAT3 in APCs [69]. In addition, IFN- $\alpha$ has also been reported to induce upregulated mRNA expression and protein 
expression of PD-L1 on microvascular endothelial cells (ECS) [70]. Moreover the enhanced expression of PD-L1 protein and mRNA was induced by IFN- $\beta$ on monocytes and mature dendritic cells of healthy donors and multiple sclerosis (MS) patients [71].

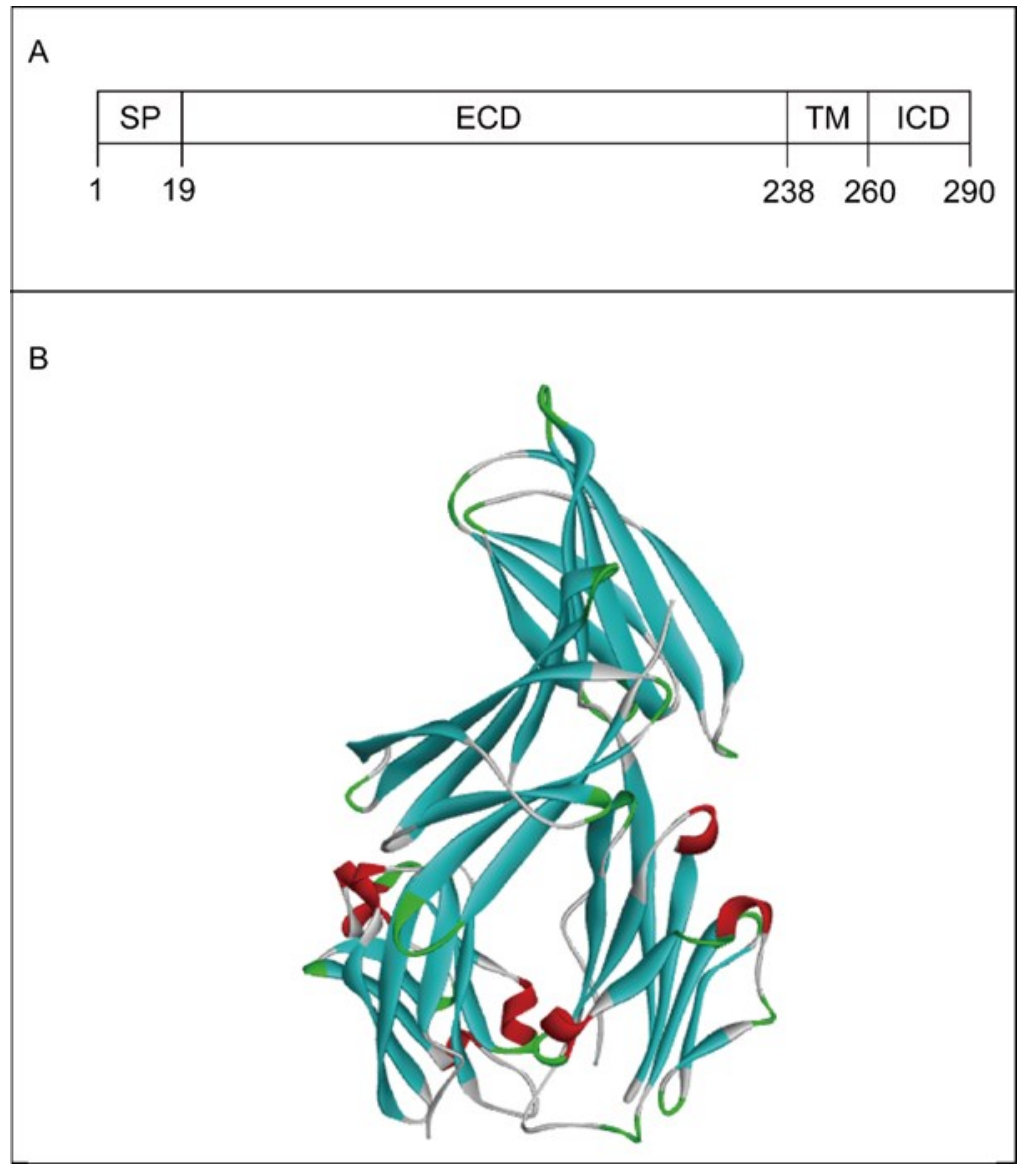

Figure 1. Schematic diagram and structure of PD-L1 protein. A. Schematic diagram of PD-L1 protein. SP: Signal peptide; ECD: Extracellular Domain; TM: Transmembrane Domain; ICD; Intracellular domain. B. Structure of PD-L1 protein. This structure shows two main anti-parallel $\beta$ sandwich immunoglobulin superfamily (Ig SF) domains of $\mathrm{PD}=\mathrm{L} 1$ protein.

Inflammatory macrophages upregulate expression of PD-L1, which was also induced by lipopolysaccharide (LPS) [72]. Enhanced expression of PD-L1 was present on immature dendritic cells (iDCs) after being treated with granulocyte-macrophage colony-stimulating factor (GM-CSF) [73]. Ou et al. reported that in SLE monocytes opposing actions of TNF- $\alpha$ and Transforming growth factor (TGF)- $\beta$ regulated the expression of PD-L1 [74]. PD-L1 expression could be revived by exogenous TNF- $\alpha$ on lupus monocytes [74]. TGF- $\beta$ has shown to inhibit PD-L1 expression on monocytes [74]. Induction of PD-L1 expression is also associated with Janus kinase (JAK)/STAT signaling and Activator protein 1 (AP1) activity [75]. Michael et al. showed that in classical Hodgkin lymphoma Reed-Sternberg cells constitutive activation of AP-1 resulted in the binding of AP-1 components to enhancer of CD274 gene, which enhanced the activity of PD-L1 promoter [75]. The induction of PD-L1 expression by JAK2 was also observed in this study, which was associated with JAK/STAT-dependent promoter in CD274 gene [75]. Besides, the increase of PDL1 expression protein was induced by inhibition of phosphatase and tensin homolog (PTEN) in glioma cancer and colorectal cancer [22]. Recent studies reported that PD-L1 expression was inhibited by p53 through regulating miR-34a and miR-200 [76, 77].

The IL family also was indicated to be important for induction of PD-L1 expression. For instance, IL-27 enhanced the expression of CD274 gene which is dependent on STAT1 on naïve T cells [78]. Further study 
showed that PD-L1 expression was increased which was mediated by IL-4 in nuclear factor-kappa B (NF-kB) p50-/- p65+/- dendritic cell (DC) [38].

The PD-L1 expression was not only induced by multiple pro-inflammatory molecules, but also influenced by T cells. For example, enhanced expression of PD-L1 induced by Type 1 T helper (Th1) cells was also found on different macrophages [72]. Activation of human T cells by anti-CD3 and anti-CD28 may lead to increased expression of PD-L1 mRNA [79].

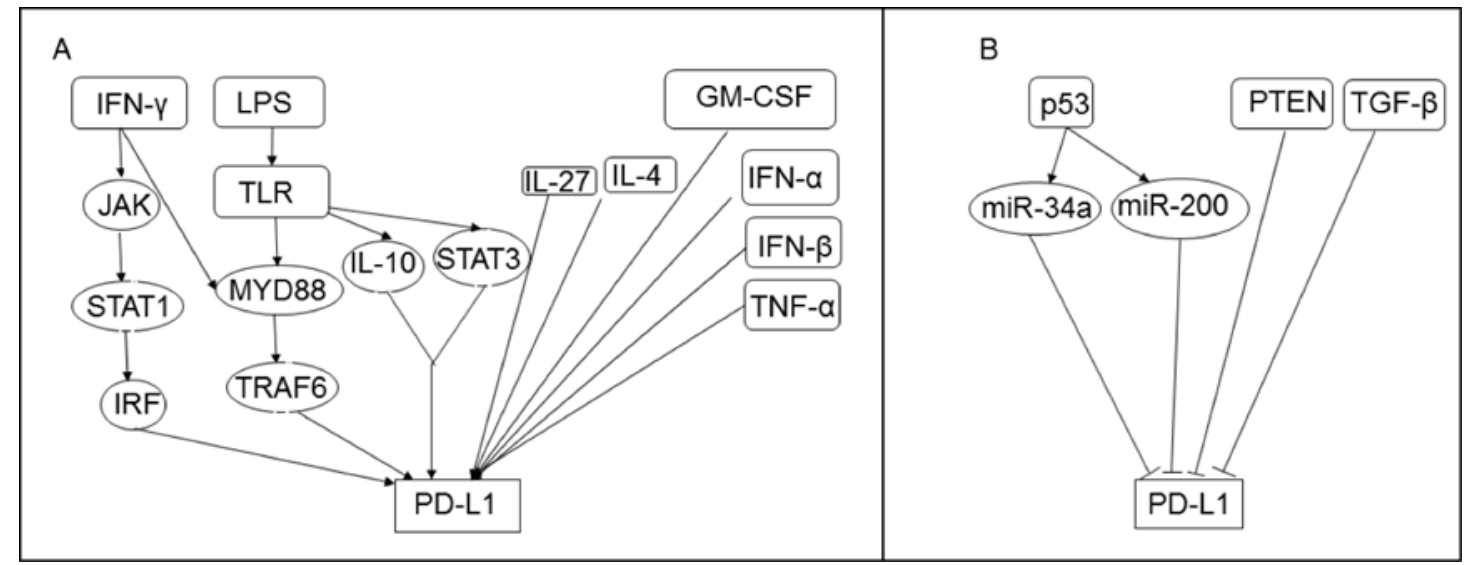

Figure 2. PD-L1 expression is regulated by several cytokines. A. Upregulation of PD-L1 is induced by various pro-inflammatory molecules. PD-L1 could be induced by IFN- $\gamma$ and TLR ligands via regulation of downstream adaptor proteins of the TLR signaling pathway. IFN- $\gamma$ also induced PD-L1 expression through JAK-STAT1 signaling pathway. Except that, some other cytokines, like GM-CSF, TNF-alpha, IL, can increase PD-L1 expression. B. Inhibition of PD-L1 expression is mediated by p53, PTEN and TGF- $\beta$.

\section{PD-L1/PD-1 signaling pathway}

Several studies reported that PD-L1 can interact with PD-1, and this interaction delivered an inhibitory signals to regulate immune tolerance and immunopathology [80]. Most importantly, PD-L1/PD-1 signaling may exert its inhibitory effect on immune response through signaling pathway mediated by various types of cytokines, such as SHP-1, TCR, Phosphoinositide 3-kinase (PI3K). Figure 3 shows PD-L1/PD-1 signaling pathway regulating $T$ cell survival.

The effector T cells interaction of PD-L1 and PD-1 blocked TCR signal transduction, leading to inhibition of T cell cytotoxic activity [81]. The Src homology region 2 domain containing phosphatase-1 (SHP1) could regulate activation of CD8+ T cell and inhibition of SHP-1 by sodium stibogluconate enhanced the function of $\mathrm{T}$ cells [82]. The cytoplasmic domain of PD-1 consists of two motifs, including the tyrosine-based inhibitory motif (ITIM) and immunoreceptor tyrosine-based switch motif (ITSM) [83]. The PD-1 and PD-L1 interaction can phosphorylate a tyrosine in the ITSM motif of PD-1, and then recruit the SHP-1 and SHP2 to the ITSM motif [84]. After recruiting, this signaling pathway can inhibit stop signals, and block the interaction of $T$ cells and dendritic cells [85]. Finally, blockade of the TCR signal transduction caused inhibition of the PI3K/AKT (AKT is known as Protein kinase B) and MAPK signaling [86]. Most importantly, inhibition of PI3K activation suppresses the expression of B cell lymphoma extra-large $(B c l-x L)$ and activation of AKT, which furtherly leads to increased apoptosis of T cells [12].

PD-L1 not only inhibits function of activated T cell via inhibition of PI3K/AKT pathway and Ras/MEK/ERK pathway, but also through inhibition of transcription factors necessary for T cell survival. PD-L1 and PD-1 interaction was reported to inhibit expression of GATA-3 and T-bet [87]. GATA-3 has been reported to be a 
transcription factor which is critical for differentiation of T helper 2 (Th2) cells [21]. Meanwhile, T-bet, which is known as T-box transcription factor, can contribute to T-cell development [88].

PD-L1/PD-1 interaction is also involved in signal pathway mediated by TGF- $\beta$. Loise et al. reported that the function of TGF- $\beta$ in induced T cell regulatory (iTreg) cell development could be reduced by the loss of PD-L1 [89]. This study also reported that during the conversion of iTreg cells from mature T cells, PD-L1/PD1 signaling reduced the phosphorylation of AKT and its downstream substrates mTOR and S6 [89].

Barber et al. reported that in exhausted CD8+ T cell blockade of PD-L1 and PD-1 signaling pathway enhanced T cell ability to secrete cytokine and kill infected cells with LCMV, suggesting that the PD-L1/PD-1 signaling pathway affected activation of downstream molecules of the T cell activation [51]. The study reported by Carter et al. showed that PD-L1 and PD-1 interaction inhibited IL-2 production in CD4+ and CD8+ T cell, which further inhibited lymphoproliferation [90]. In endothelial cells mouse anti-PD-L1 blocked the interaction of PD-L1 and PD-I, and stimulated IFN- $\gamma$ production secreted by CD8+ T cell, resulting in T cell activation [91]. In Hodgkin lymphoma -infiltrating T cells, inhibition of the activation of PD-1 and PD-L1 signaling pathway led to inhibition of SHP-2 phosphorylation and increased the production of IFN- $\gamma$ [92]. In the liver PD-L1 and PD-1 interaction led to reduced IFN $-\psi$ production secreted by CD8+ T Lymphocytes(CLT) [50].

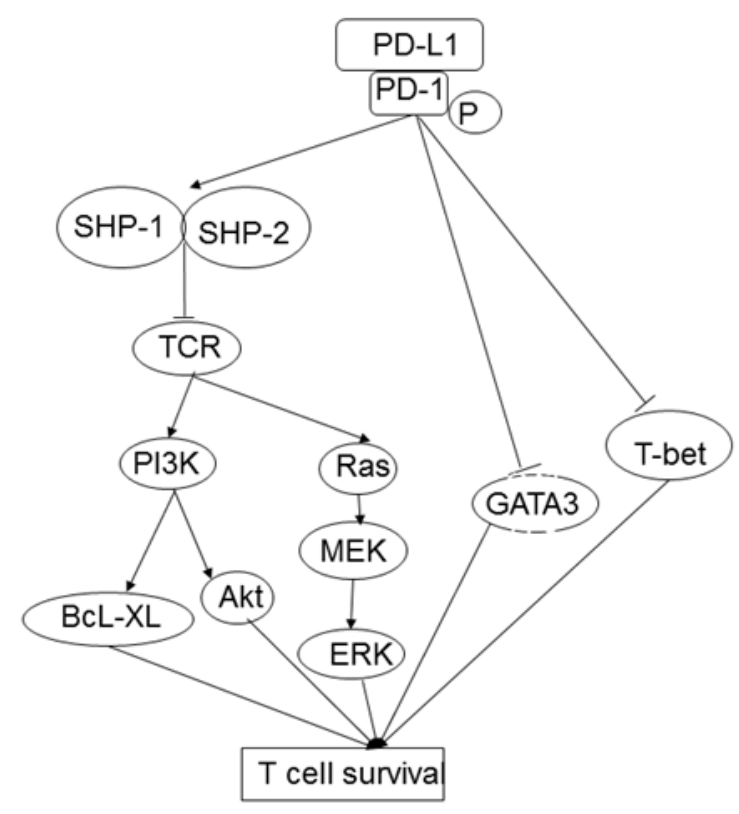

Figure 3. The PD-L1/PD-1 signaling pathway in T cells. PD-L1/PD1 signaling pathway could mediate T cell survival through regulation of different signal transductions. PD-1 and PD-L1 interaction leads to PD-1 phosphorylation, and recruits SHP-1 and SHP2 to the ITSM motif of PD-1. After recruiting, this signaling pathway blocks the interaction of T cells. Blockade of TCR signal transduction inhibited the PI3k/Akt and MAPK signaling. Inhibition of PI3K activation suppressed the expression of B cell lymphoma extra-large (Bcl-xL) and activation of Akt, which leads to increased apoptosis of T cells. PD-L1 and PD-1 interaction also inhibits expression of GATA-3 and T-bet. GATA-3 is critical for differentiation of Th2 cells. T-bet contributes to T-cell development.

\section{Conclusions}

This review describes the regulation of the PD-L1/PD-1 signaling pathway. PD-L1 is a transmembrane protein, and inhibits the function of T cell through binding to its receptor PD-1. The interaction of PD-L1 and PD-1 inhibits $T$ cell activation and proliferation, which inhibits the function of $T$ cells to produce cytokines and kill targeting tumor cells. Blockade of PD-L1 signaling by anti-PD-L1 antibodies not only 
inhibits tumor growth, but also leads to etiopathogenetic of autoimmune diseases (such as diabetes). There are several kinds of antibodies in development against PD-L1 in cancer immunotherapy, such as atezolizumab, avelumab, durvalumab, BMS-936559. The safety study with BMS-936659 showed that in $39 \%$ patient side effects such as rash, hypothyroidism, diabetes mellitus, myasthenia gravis and other disease occurred [93]. This makes PD-L1 an attractive target for anti-cancer therapy. However, knowledge on the side effects of anti-PD-L1 therapy is still limiting and, more studies are needed to get a better in the regulation of PD-L1 on cancer.

Acknowledgements: This work was supported by the Science and Technology Development Fund of Macau SAR (FDCT) [023/2015/AMJ] and the International S\&T Cooperation Program of China [2016YFE0121900]. Miss Libin Guo was in receipt of PhD studentship from the Faculty Health Sciences University of Macau and FDCT.

\section{References}

[1] Z. Lian, Y. Xie, Y. Lu, D. Huang, H. Shi. Trends in the major causes of death in China, 1982-2010, Chin Med J (Engl) 127 (2014) 777-781.

[2] R.L. Siegel, K.D. Miller, A. Jemal. Cancer Statistics, 2017, CA Cancer J Clin 67 (2017) 7-30.

[3] L. Yang, L. Wang, Y. Zhang. Immunotherapy for lung cancer: advances and prospects, Am J Clin Exp Immunol 5 (2016) 1-20.

[4] G. Lezoche, A.M. Paganini, R. Campagnacci, R. Ghiselli, M. Pelloni, A. Rombini, M. Guerrieri. Treatment of rectal cancer by transanal endoscopic microsurgery: review of the literature, Minerva Chir 68 (2013) 1-9.

[5] A. Munshi, J.P. Agarwal, K.C. Pandey. Cancer patients with cardiac pacemakers needing radiation treatment: a systematic review, J Cancer Res Ther 9 (2013) 193-198.

[6] M. Johnson. Chemotherapy treatment decision making by professionals and older patients with cancer: a narrative review of the literature, Eur J Cancer Care (Engl) 21 (2012) 3-9.

[7] A.M. Manganoni, C. Zane, L. Pavoni, C. Farisoglio, E. Sereni, P. Calzavara-Pinton. Cutaneous melanoma in patients in treatment with biological therapy: review of the literature and case report, Dermatol Online J 17 (2011) 12.

[8] M. Kudo. Targeted therapy for liver cancer: updated review in 2012, Curr Cancer Drug Targets 12 (2012) 1062-1072.

[9] D.G. Maloney, A.J. GrilloLopez, C.A. White, D. Bodkin, R.J. Schilder, J.A. Neidhart, N. Janakiraman, K.A. Foon, T.M. Liles, B.K. Dallaire, K. Wey, I. Royston, T. Davis, R. Levy. IDEC-C2B8 (Rituximab) antiCD20 monoclonal antibody therapy in patients with relapsed low-grade non-Hodgkin's lymphoma, Blood 90 (1997) 2188-2195.

[10] I. Mellman, G. Coukos, G. Dranoff. Cancer immunotherapy comes of age, Nature 480 (2011) 480489.

[11] C. Guo, M.H. Manjili, J.R. Subjeck, D. Sarkar, P.B. Fisher, X.Y. Wang. Therapeutic cancer vaccines: past, present, and future, Adv Cancer Res 119 (2013) 421-475.

[12] M. Themeli, I. Riviere, M. Sadelain. New cell sources for $T$ cell engineering and adoptive immunotherapy, Cell Stem Cell 16 (2015) 357-366.

[13] S.J. Russell, K.W. Peng, J.C. Bell. Oncolytic virotherapy, Nat Biotechnol 30 (2012) 658-670.

[14] L. Galluzzi, E. Vacchelli, J.M. Bravo-San Pedro, A. Buque, L. Senovilla, E.E. Baracco, N. Bloy, F. Castoldi, J.P. Abastado, P. Agostinis, R.N. Apte, F. Aranda, M. Ayyoub, P. Beckhove, J.Y. Blay, L. Bracci, A. Caignard, C. Castelli, F. Cavallo, E. Celis, V. Cerundolo, A. Clayton, M.P. Colombo, L. Coussens, M.V. Dhodapkar, A.M. Eggermont, D.T. Fearon, W.H. Fridman, J. Fucikova, D.I. Gabrilovich, J. Galon, A. Garg, F. Ghiringhelli, G. Giaccone, E. Gilboa, S. Gnjatic, A. Hoos, A. 
Hosmalin, D. Jager, P. Kalinski, K. Karre, O. Kepp, R. Kiessling, J.M. Kirkwood, E. Klein, A. Knuth, C.E. Lewis, R. Liblau, M.T. Lotze, E. Lugli, J.P. Mach, F. Mattei, D. Mavilio, I. Melero, C.J. Melief, E.A. Mittendorf, L. Moretta, A. Odunsi, H. Okada, A.K. Palucka, M.E. Peter, K.J. Pienta, A. Porgador, G.C. Prendergast, G.A. Rabinovich, N.P. Restifo, N. Rizvi, C. Sautes-Fridman, H. Schreiber, B. Seliger, H. Shiku, B. Silva-Santos, M.J. Smyth, D.E. Speiser, R. Spisek, P.K. Srivastava, J.E. Talmadge, E. Tartour, S.H. Van Der Burg, B.J. Van Den Eynde, R. Vile, H. Wagner, J.S. Weber, T.L. Whiteside, J.D. Wolchok, L. Zitvogel, W. Zou, G. Kroemer. Classification of current anticancer immunotherapies, Oncotarget 5 (2014) 12472-12508.

[15] S. Carvalho, F. Levi-Schaffer, M. Sela, Y. Yarden. Immunotherapy of cancer: from monoclonal to oligoclonal cocktails of anti-cancer antibodies: IUPHAR Review 18, Brit J Pharmacol 173 (2016) 1407-1424.

[16] R.G. Amado, M. Wolf, M. Peeters, E. Van Cutsem, S. Siena, D.J. Freeman, T. Juan, R. Sikorski, S. Suggs, R. Radinsky, S.D. Patterson, D.D. Chang. Wild-type KRAS is required for panitumumab efficacy in patients with metastatic colorectal cancer, J Clin Oncol 26 (2008) 1626-1634.

[17] J.R. Thompson, S.P. Menon, G.K. Dy. Tyrosine kinase inhibitors for EGFR-and ALK-mutated nonsmall cell lung cancer, ADMET and DMPK 4 (2016) 186-211.

[18] S.J. Demarest, K. Hariharan, J. Dong. Emerging antibody combinations in oncology, MAbs 3 (2011) 338-351.

[19] E.A. Hawkes, A. Grigg, G. Chong. Programmed cell death-1 inhibition in lymphoma, Lancet Oncol 16 (2015) E234-E245.

[20] J. Liu, A. Hamrouni, D. Wolowiec, V. Coiteux, K. Kuliczkowski, D. Hetuin, A. Saudemont, B. Quesnel. Plasma cells from multiple myeloma patients express B7-H1 (PD-L1) and increase expression after stimulation with IFN-\{gamma\} and TLR ligands via a MyD88-, TRAF6-, and MEK-dependent pathway, Blood 110 (2007) 296-304.

[21] J.F. Jacobs, A.J. Idema, K.F. Bol, S. Nierkens, O.M. Grauer, P. Wesseling, J.A. Grotenhuis, P.M. Hoogerbrugge, I.J. de Vries, G.J. Adema. Regulatory T cells and the PD-L1/PD-1 pathway mediate immune suppression in malignant human brain tumors, Neuro Oncol 11 (2009) 394-402.

[22] A.T. Parsa, J.S. Waldron, A. Panner, C.A. Crane, I.F. Parney, J.J. Barry, K.E. Cachola, J.C. Murray, T. Tihan, M.C. Jensen, P.S. Mischel, D. Stokoe, R.O. Pieper. Loss of tumor suppressor PTEN function increases B7-H1 expression and immunoresistance in glioma, Nat Med 13 (2007) 84-88.

[23] S.E. Strome, H. Dong, H. Tamura, S.G. Voss, D.B. Flies, K. Tamada, D. Salomao, J. Cheville, F. Hirano, W. Lin, J.L. Kasperbauer, K.V. Ballman, L. Chen. B7-H1 blockade augments adoptive T-cell immunotherapy for squamous cell carcinoma, Cancer Res 63 (2003) 6501-6505.

[24] J.C. Routh, R.A. Ashley, T.J. Sebo, C.M. Lohse, D.A. Husmann, S.A. Kramer, E.D. Kwon. B7-H1 expression in Wilms tumor: Correlation with tumor biology and disease recurrence, J Urology 179 (2008) 1954-1959.

[25] R. Hino, K. Kabashima, Y. Kato, H. Yagi, M. Nakamura, T. Honjo, T. Okazaki, Y. Tokura. Tumor Cell Expression of Programmed Cell Death-1 Ligand 1 Is a Prognostic Factor for Malignant Melanoma, Cancer-Am Cancer Soc 116 (2010) 1757-1766.

[26] J. Hamanishi, M. Mandai, M. Iwasaki, T. Okazaki, Y. Tanaka, K. Yamaguchi, T. Higuchi, H. Yagi, K. Takakura, N. Minato, T. Honjo, S. Fujii. Programmed cell death 1 ligand 1 and tumor-infiltrating CD8+ T lymphocytes are prognostic factors of human ovarian cancer, Proc Natl Acad Sci U S A 104 (2007) 3360-3365.

[27] J. Konishi, K. Yamazaki, M. Azuma, I. Kinoshita, H. Dosaka-Akita, M. Nishimura. B7-h1 expression on non-small cell lung cancer cells and its relationship with tumor-infiltrating lymphocytes and their PD-1 expression, Clin Cancer Res 10 (2004) 5094-5100.

[28] J. Nakanishi, Y. Wada, K. Matsumoto, M. Azuma, K. Kikuchi, S. Ueda. Overexpression of B7-H1 (PDL1) significantly associates with tumor grade and postoperative prognosis in human urothelial cancers, Cancer Immunol Immun 56 (2007) 1173-1182. 
[29] Y. Ohigashi, M. Sho, Y. Yamada, Y. Tsurui, K. Hamada, N. Ikeda, T. Mizuno, R. Yoriki, H. Kashizuka, K. Yane, F. Tsushima, N. Otsuki, H. Yagita, M. Azuma, Y. Nakajima. Clinical significance of programmed death-1 ligand-1 and programmed death-1 ligand-2 expression in human esophageal cancer, Clin Cancer Res 11 (2005) 2947-2953.

[30] R. Karim, E.S. Jordanova, S.J. Piersma, G.G. Kenter, L. Chen, J.M. Boer, C.J. Melief, S.H. van der Burg. Tumor-expressed $\mathrm{B} 7-\mathrm{H} 1$ and $\mathrm{B} 7-\mathrm{DC}$ in relation to PD-1+ T-cell infiltration and survival of patients with cervical carcinoma, Clin Cancer Res 15 (2009) 6341-6347.

[31] T. Nomi, M. Sho, T. Akahori, K. Hamada, A. Kubo, H. Kanehiro, S. Nakamura, K. Enomoto, H. Yagita, M. Azuma, Y. Nakajima. Clinical significance and therapeutic potential of the programmed death-1 ligand/programmed death-1 pathway in human pancreatic cancer, Clin Cancer Res 13 (2007) 21512157.

[32] Z. Zeng, F. Shi, L. Zhou, M.N. Zhang, Y. Chen, X.J. Chang, Y.Y. Lu, W.L. Bai, J.H. Qu, C.P. Wang, H. Wang, M. Lou, F.S. Wang, J.Y. LV, Y.P. Yang. Upregulation of Circulating PD-L1/PD-1 Is Associated with Poor Post-Cryoablation Prognosis in Patients with HBV-Related Hepatocellular Carcinoma, Plos One 6 (2011).

[33] S. Muenst, A.R. Schaerli, F. Gao, S. Daster, E. Trella, R.A. Droeser, M.G. Muraro, P. Zajac, R. Zanetti, W.E. Gillanders, W.P. Weber, S.D. Soysal. Expression of programmed death ligand 1 (PD-L1) is associated with poor prognosis in human breast cancer, Breast Cancer Res $\operatorname{Tr} 146$ (2014) 15-24.

[34] C.T. Wu, W.C. Chen, Y.H. Chang, W.Y. Lin, M.F. Chen. The role of PD-L1 in the radiation response and clinical outcome for bladder cancer, Sci Rep 6 (2016) 19740.

[35] S. Derks, X.Y. Liao, A.M. Chiaravalli, X.S. Xu, M.C. Camargo, E. Solcia, F. Sessa, T. Fleitas, G.J. Freeman, S.J. Rodig, C.S. Rabkin, A.J. Bass. Abundant PD-L1 expression in Epstein-Barr Virusinfected gastric cancers, Oncotarget 7 (2016) 32925-32932.

[36] L. Zhang, T.F. Gajewski, J. Kline. PD-1/PD-L1 interactions inhibit antitumor immune responses in a murine acute myeloid leukemia model, Blood 114 (2009) 1545-1552.

[37] Y. Iwai, M. Ishida, Y. Tanaka, T. Okazaki, T. Honjo, N. Minato. Involvement of PD-L1 on tumor cells in the escape from host immune system and tumor immunotherapy by PD-L1 blockade, Proc Natl Acad Sci U S A 99 (2002) 12293-12297.

[38] S.C. Liang, Y.E. Latchman, J.E. Buhlmann, M.F. Tomczak, B.H. Horwitz, G.J. Freeman, A.H. Sharpe. Regulation of PD-1, PD-L1, and PD-L2 expression during normal and autoimmune responses, Eur J Immunol 33 (2003) 2706-2716.

[39] M.J. Ansari, A.D. Salama, T. Chitnis, R.N. Smith, H. Yagita, H. Akiba, T. Yamazaki, M. Azuma, H. Iwai, S.J. Khoury, H. Auchincloss, Jr., M.H. Sayegh. The programmed death-1 (PD-1) pathway regulates autoimmune diabetes in nonobese diabetic (NOD) mice, J Exp Med 198 (2003) 63-69.

[40] T.L. Delovitch, B. Singh. The nonobese diabetic mouse as a model of autoimmune diabetes: Immune dysregulation gets the NOD, Immunity 7 (1997) 727-738.

[41] B. Zhu, I. Guleria, A. Khosroshahi, T. Chitnis, J. Imitola, M. Azuma, H. Yagita, M.H. Sayegh, S.J. Khoury. Differential role of programmed death-ligand 1 [corrected] and programmed death-ligand 2 [corrected] in regulating the susceptibility and chronic progression of experimental autoimmune encephalomyelitis, J Immunol 176 (2006) 3480-3489.

[42] S. Bodhankar, D. Galipeau, A.A. Vandenbark, H. Offner. PD-1 Interaction with PD-L1 but not PD-L2 on B-cells Mediates Protective Effects of Estrogen against EAE, J Clin Cell Immunol 4 (2013) 143.

[43] M. Kobayashi, S. Kawano, S. Hatachi, C. Kurimoto, T. Okazaki, Y. Iwai, T. Honjo, Y. Tanaka, N. Minato, T. Komori, S. Maeda, S. Kumagai. Enhanced expression of programmed death-1 (PD-1)/PDL1 in salivary glands of patients with Sjogren's syndrome, J Rheumatol 32 (2005) 2156-2163.

[44] M.F. Liu, C.T. Weng, M.Y. Weng. Variable Increased Expression of Program Death-1 and Program Death-1 Ligands on Peripheral Mononuclear Cells Is Not Impaired in Patients with Systemic Lupus Erythematosus, J Biomed Biotechnol (2009).

[45] T. Kanai, T. Totsuka, K. Uraushihara, S. Makita, T. Nakamura, K. Koganei, T. Fukushima, H. Akiba, H. Yagita, K. Okumura, T. Machida, H. Iwai, M. Azuma, L.P. Chen, M. Watanabe. Blockade of B7-H1 
suppresses intestinal inflammation the development of chronic, Journal of Immunology 171 (2003) 4156-4163.

[46] Z. Xie, Y. Chen, S. Zhao, Z. Yang, X. Yao, S. Guo, C. Yang, L. Fei, X. Zeng, B. Ni, Y. Wu. Intrahepatic PD1/PD-L1 up-regulation closely correlates with inflammation and virus replication in patients with chronic HBV infection, Immunol Invest 38 (2009) 624-638.

[47] A. Kassem, A. Schopflin, C. Diaz, W. Weyers, E. Stickeler, M. Werner, A. Zur Hausen. Frequent detection of Merkel cell polyomavirus in human Merkel cell carcinomas and identification of a unique deletion in the VP1 gene, Cancer Res 68 (2008) 5009-5013.

[48] E.J. Lipson, J.G. Vincent, M. Loyo, L.T. Kagohara, B.S. Luber, H. Wang, H. Xu, S.K. Nayar, T.S. Wang, D. Sidransky, R.A. Anders, S.L. Topalian, J.M. Taube. PD-L1 expression in the Merkel cell carcinoma microenvironment: association with inflammation, Merkel cell polyomavirus and overall survival, Cancer Immunol Res 1 (2013) 54-63.

[49] J.K. Whitmire, J.T. Tan, J.L. Whitton. Interferon-gamma acts directly on CD8(+) T cells to increase their abundance during virus infection, Journal of Experimental Medicine 201 (2005) 1053-1059.

[50] H. Maier, M. Isogawa, G.J. Freeman, F.V. Chisari. PD-1:PD-L1 interactions contribute to the functional suppression of virus-specific CD8+ T lymphocytes in the liver, J Immunol 178 (2007) 2714-2720.

[51] D.L. Barber, E.J. Wherry, D. Masopust, B. Zhu, J.P. Allison, A.H. Sharpe, G.J. Freeman, R. Ahmed. Restoring function in exhausted CD8 T cells during chronic viral infection, Nature 439 (2006) 682687.

[52] L. Trautmann, L. Janbazian, N. Chomont, E.A. Said, S. Gimmig, B. Bessette, M.R. Boulassel, E. Delwart, H. Sepulveda, R.S. Balderas, J.P. Routy, E.K. Haddad, R.P. Sekaly. Upregulation of PD-1 expression on HIV-specific CD8(+) T cells leads to reversible immune dysfunction (vol 12, 1198, 2006), Nature Medicine 12 (2006) 1329-1329.

[53] S. Urbani, B. Amadei, D. Tola, G. Pedrazzi, L. Sacchelli, M.C. Cavallo, A. Orlandini, G. Missale, C. Ferrari. Restoration of HCV-specific T cell functions by PD-1/PD-L1 blockade in HCV infection: effect of viremia levels and antiviral treatment, J Hepatol 48 (2008) 548-558.

[54] B.B. Dai, L. Xiao, P.D. Bryson, J.X. Fang, P. Wang. PD-1/PD-L1 Blockade Can Enhance HIV-1 Gagspecific T Cell Immunity Elicited by Dendritic Cell-Directed Lentiviral Vaccines, Mol Ther 20 (2012) 1800-1809.

[55] S.Y. Liu, Y.L. Wu. Ongoing clinical trials of PD-1 and PD-L1 inhibitors for lung cancer in China, $J$ Hematol Oncol 10 (2017) 136.

[56] A.I. Daud, K. Loo, M.L. Pauli, R. Sanchez-Rodriguez, P.M. Sandoval, K. Taravati, K. Tsai, A. Nosrati, L. Nardo, M.D. Alvarado, A.P. Algazi, M.H. Pampaloni, I.V. Lobach, J. Hwang, R.H. Pierce, I.K. Gratz, M.F. Krummel, M.D. Rosenblum. Tumor immune profiling predicts response to anti-PD-1 therapy in human melanoma, J Clin Invest 126 (2016) 3447-3452.

[57] N.H. Segal, S.H.I. Ou, A.S. Balmanoukian, M.G. Fury, E. Massarelli, J.R. Brahmer, J. Weiss, P. Schoffski, S.J. Antonia, C. Massard, D.P. Zandberg, S. Khleif, X. Li, M. Rebelatto, K. Steele, P.B. Robbins, J.A. Blake-Haskins, M.O. Butler. Safety and efficacy of MEDI4736, an anti-PD-L1 antibody, in patients from a squamous cell carcinoma of the head and neck (SCCHN) expansion cohort., $J$ Clin Oncol 33 (2015).

[58] N.J. Llosa, M. Cruise, A. Tam, E.C. Wicks, E.M. Hechenbleikner, J.M. Taube, R.L. Blosser, H.N. Fan, H. Wang, B.S. Luber, M. Zhang, N. Papadopoulos, K.W. Kinzler, B. Vogelstein, C.L. Sears, R.A. Anders, D.M. Pardoll, F. Housseau. The Vigorous Immune Microenvironment of Microsatellite Instable Colon Cancer Is Balanced by Multiple Counter-Inhibitory Checkpoints, Cancer Discov 5 (2015) 4351.

[59] D. Liu, S. Wang, W. Bindeman. Clinical applications of PD-L1 bioassays for cancer immunotherapy, J Hematol Oncol 10 (2017) 110.

[60] J. Chen, C.C. Jiang, L. Jin, X.D. Zhang. Regulation of PD-L1: a novel role of pro-survival signalling in cancer, Ann Oncol 27 (2016) 409-416. 
[61] N. Chen, W.F. Fang, J.H. Zhan, S.D. Hong, Y.N. Tang, S.Y. Kang, Y.X. Zhang, X.B. He, T. Zhou, T. Qin, Y. Huang, X.P. Yi, L. Zhang. Upregulation of PD-L1 by EGFR Activation Mediates the Immune Escape in EGFR-Driven NSCLC Implication for Optional Immune Targeted Therapy for NSCLC Patients with EGFR Mutation, J Thorac Oncol 10 (2015) 910-923.

[62] H. Dong, G. Zhu, K. Tamada, L. Chen. B7-H1, a third member of the B7 family, co-stimulates T-cell proliferation and interleukin-10 secretion, Nat Med 5 (1999) 1365-1369.

[63] G.J. Freeman, A.J. Long, Y. Iwai, K. Bourque, T. Chernova, H. Nishimura, L.J. Fitz, N. Malenkovich, T. Okazaki, M.C. Byrne, H.F. Horton, L. Fouser, L. Carter, V. Ling, M.R. Bowman, B.M. Carreno, M. Collins, C.R. Wood, T. Honjo. Engagement of the PD-1 immunoinhibitory receptor by a novel B7 family member leads to negative regulation of lymphocyte activation, J Exp Med 192 (2000) 10271034.

[64] M.M. Mazanet, C.C.W. Hughes. B7-H1 is expressed by human endothelial cells and suppresses T cell cytokine synthesis, Journal of Immunology 169 (2002) 3581-3588.

[65] M. Collins, V. Ling, B.M. Carreno. The B7 family of immune-regulatory ligands, Genome Biol 6 (2005) 223.

[66] Y. Chen, P. Liu, F. Gao, H. Cheng, J. Qi, G.F. Gao. A dimeric structure of PD-L1: functional units or evolutionary relics?, Protein Cell 1 (2010) 153-160.

[67] M.J. Butte, M.E. Keir, T.B. Phamduy, A.H. Sharpe, G.J. Freeman. Programmed death-1 ligand 1 interacts specifically with the B7-1 costimulatory molecule to inhibit T cell responses, Immunity 27 (2007) 111-122.

[68] S.J. Lee, B.C. Jang, S.W. Lee, Y.I. Yang, S.I. Suh, Y.M. Park, S. Oh, J.G. Shin, S. Yao, L.P. Chen, I.H. Choi. Interferon regulatory factor-1 is prerequisite to the constitutive expression and IFN-gammainduced upregulation of B7-H1 (CD274), Febs Lett 580 (2006) 755-762.

[69] S.J. Wolfle, J. Strebovsky, H. Bartz, A. Sahr, C. Arnold, C. Kaiser, A.H. Dalpke, K. Heeg. PD-L1 expression on tolerogenic APCs is controlled by STAT-3, European Journal of Immunology 41 (2011) 413-424.

[70] M.J. Eppihimer, J. Gunn, G.J. Freeman, E.A. Greenfield, T. Chernova, J. Erickson, J.P. Leonard. Expression and regulation of the PD-L1 immunoinhibitory molecule on microvascular endothelial cells, Microcirculation 9 (2002) 133-145.

[71] B. Schreiner, M. Mitsdoerffer, B.C. Kieseier, L. Chen, H.P. Hartung, M. Weller, H. Wiendl. Interferonbeta enhances monocyte and dendritic cell expression of B7-H1 (PD-L1), a strong inhibitor of autologous T-cell activation: relevance for the immune modulatory effect in multiple sclerosis, $J$ Neuroimmunol 155 (2004) 172-182.

[72] P. Loke, J.P. Allison. PD-L1 and PD-L2 are differentially regulated by Th1 and Th2 cells, Proc Nat/ Acad Sci U S A 100 (2003) 5336-5341.

[73] J.A. Brown, D.M. Dorfman, F.R. Ma, E.L. Sullivan, O. Munoz, C.R. Wood, E.A. Greenfield, G.J. Freeman. Blockade of programmed death-1 ligands on dendritic cells enhances $T$ cell activation and cytokine production, J Immunol 170 (2003) 1257-1266.

[74] J.N. Ou, A.E. Wiedeman, A.M. Stevens. TNF-alpha and TGF-beta counter-regulate PD-L1 expression on monocytes in systemic lupus erythematosus, Sci Rep 2 (2012) 295.

[75] M.R. Green, S. Rodig, P. Juszczynski, J. Ouyang, P. Sinha, E. O'Donnel. Constitutive AP-1 Activity and EBV Infection Induce PD-L1 in Hodgkin Lymphomas and Posttransplant Lymphoproliferative Disorders: Implications for Targeted Therapy (vol 18, pg 1611, 2012), Clin Cancer Res 18 (2012) 2117-2117.

[76] T. Kim, A. Veronese, F. Pichiorri, T.J. Lee, Y.J. Jeon, S. Volinia, P. Pineau, A. Marchio, J. Palatini, S.S. Suh, H. Alder, C.G. Liu, A. Dejean, C.M. Croce. p53 regulates epithelial-mesenchymal transition through microRNAs targeting ZEB1 and ZEB2, Journal of Experimental Medicine 208 (2011) 875883. 
[77] X. Wang, J.G. Li, K. Dong, F. Lin, M. Long, Y.R. Ouyang, J.X. Wei, X. Chen, Y.Y. Weng, T. He, H.Z. Zhang. Tumor suppressor miR-34a targets PD-L1 and functions as a potential immunotherapeutic target in acute myeloid leukemia, Cell Signal 27 (2015) 443-452.

[78] K. Hirahara, K. Ghoreschi, X.P. Yang, H. Takahashi, A. Laurence, G. Vahedi, G. Sciume, A.O. Hall, C.D. Dupont, L.M. Francisco, Q. Chen, M. Tanaka, Y. Kanno, H.W. Sun, A.H. Sharpe, C.A. Hunter, J.J. O'Shea. Interleukin-27 Priming of T Cells Controls IL-17 Production In trans via Induction of the Ligand PD-L1, Immunity 36 (2012) 1017-1030.

[79] F. Bennett, D. Luxenberg, V. Ling, I.M. Wang, K. Marquette, D. Lowe, N. Khan, G. Veldman, K.A. Jacobs, V.E. Valge-Archer, M. Collins, B.M. Carreno. Program death-1 engagement upon TCR activation has distinct effects on costimulation and cytokine-driven proliferation: Attenuation of ICOS, IL-4, and IL-21, but not CD28, IL-7, and IL-15 responses, Journal of Immunology 170 (2003) 711-718.

[80] M.E. Keir, M.J. Butte, G.J. Freeman, A.H. Sharpel. PD-1 and its ligands in tolerance and immunity, Annu Rev Immunol 26 (2008) 677-704.

[81] K. Karwacz, F. Arce, C. Bricogne, G. Kochan, D. Escors. PD-L1 co-stimulation, ligand-induced TCR down-modulation and anti-tumor immunotherapy, Oncoimmunology 1 (2012) 86-88.

[82] M. Hebeisen, L. Baitsch, D. Presotto, P. Baumgaertner, P. Romero, O. Michielin, D.E. Speiser, N. Rufer. SHP-1 phosphatase activity counteracts increased T cell receptor affinity, Journal of Clinical Investigation 123 (2013) 1044-1056.

[83] L.M. Shlapatska, S.V. Mikhalap, A.G. Berdova, O.M. Zelensky, T.J. Yun, K.E. Nichols, E.A. Clark, S.P. Sidorenko. CD150 association with either the SH2-containing inositol phosphatase or the SH2containing protein tyrosine phosphatase is regulated by the adaptor protein SH2D1A, Journal of Immunology 166 (2001) 5480-5487.

[84] J.M. Chemnitz, R.V. Parry, K.E. Nichols, C.H. June, J.L. Riley. SHP-1 and SHP-2 associate with immunoreceptor tyrosine-based switch motif of programmed death 1 upon primary human $\mathrm{T}$ cell stimulation, but only receptor ligation prevents T cell activation, Journal of Immunology 173 (2004) 945-954.

[85] B.T. Fife, K.E. Pauken, T.N. Eagar, T. Obu, J. Wu, Q.Z. Tang, M. Azuma, M.F. Krummel, J.A. Bluestone. Interactions between PD-1 and PD-L1 promote tolerance by blocking the TCR-induced stop signal, Nat Immunol 10 (2009) 1185-U1170.

[86] N. Patsoukis, J. Brown, V. Petkova, F. Liu, L. Li, V.A. Boussiotis. Selective effects of PD-1 on Akt and Ras pathways regulate molecular components of the cell cycle and inhibit T cell proliferation, $S c i$ Signal 5 (2012) ra46.

[87] R. Nurieva, S. Thomas, T. Nguyen, N. Martin-Orozco, Y. Wang, M.K. Kaja, X.Z. Yu, C. Dong. T-cell tolerance or function is determined by combinatorial costimulatory signals, EMBO J 25 (2006) 2623-2633.

[88] D.M. Dorfman, E.S. Hwang, A. Shahsafaei, L.H. Glimcher. T-bet, a T cell-associated transcription factor, is expressed in Hodgkin's lymphoma, Hum Pathol 36 (2005) 10-15.

[89] L.M. Francisco, V.H. Salinas, K.E. Brown, V.K. Vanguri, G.J. Freeman, V.K. Kuchroo, A.H. Sharpe. PD$\mathrm{L} 1$ regulates the development, maintenance, and function of induced regulatory T cells, Journal of Experimental Medicine 206 (2009) 3015-3029.

[90] L.L. Carter, L.A. Fouser, J. Jussif, L. Fitz, B. Deng, C.R. Wood, M. Collins, T. Honjo, G.J. Freeman, B.M. Carreno. PD-1 : PD-L inhibitory pathway affects both CD4(+)and CD8(+) T cells and is overcome by IL-2, European Journal of Immunology 32 (2002) 634-643.

[91] N. Rodig, T. Ryan, J.A. Allen, H. Pang, N. Grabie, T. Chernova, E.A. Greenfield, S.C. Liang, A.H. Sharpe, A.H. Lichtman, G.J. Freeman. Endothelial expression of PD-L1 and PD-L2 down-regulates CD8+ T cell activation and cytolysis, Eur J Immunol 33 (2003) 3117-3126.

[92] R. Yamamoto, M. Nishikori, T. Kitawaki, T. Sakai, M. Hishizawa, M. Tashima, T. Kondo, K. Ohmori, M. Kurata, T. Hayashi, T. Uchiyama. PD-1-PD-1 ligand interaction contributes to immunosuppressive microenvironment of Hodgkin lymphoma, Blood 111 (2008) 3220-3224. 
[93] J.R. Brahmer, S.S. Tykodi, L.Q. Chow, W.J. Hwu, S.L. Topalian, P. Hwu, C.G. Drake, L.H. Camacho, J. Kauh, K. Odunsi, H.C. Pitot, O. Hamid, S. Bhatia, R. Martins, K. Eaton, S. Chen, T.M. Salay, S. Alaparthy, J.F. Grosso, A.J. Korman, S.M. Parker, S. Agrawal, S.M. Goldberg, D.M. Pardoll, A. Gupta, J.M. Wigginton. Safety and activity of anti-PD-L1 antibody in patients with advanced cancer, $N$ Engl J Med 366 (2012) 2455-2465.

C 2017 by the authors; licensee IAPC, Zagreb, Croatia. This article is an open-access article distributed under the terms and conditions of the Creative Commons Attribution license (http://creativecommons.org/licenses/by/3.0/) (cc)) EY 